Table 1 Characteristic clinical, haematological and cytogenetic features of CGL,CNL and patient DM

\begin{tabular}{|c|c|c|c|}
\hline & $C G L$ & $C N L$ & Patient DM \\
\hline Splenomegaly & Yes & Yes & No \\
\hline $\begin{array}{l}\text { Immature } \\
\text { granulocytes in } \\
\text { peripheral blood }\end{array}$ & Frequent & Rare & Rare \\
\hline NAP & Low & High & High/normal \\
\hline $\mathrm{Ph}^{1}$ chromosome & $\begin{array}{l}\text { Present } \\
85 \%\end{array}$ & Absent $^{\star}$ & Absent \\
\hline bcr/abl hybrid gene & $\begin{array}{l}\text { Present } \\
95 \%\end{array}$ & Absent & Present \\
\hline
\end{tabular}

*There is only one report of $\mathrm{Ph}^{1}$ positive $\mathrm{CNL}$ in the English literature. $^{5}$

blood, the normal myeloblast and promyelocyte numbers in the bone marrow and the high/normal NAP score. The phenotype of this myeloproliferative disorder combined with the absence of $\mathrm{Ph}^{1}$ chromosome would, in the premolecular era, be sufficient for a diagnosis of CNL. A Medline search of the English literature identified only one case of CNL in which the $\mathrm{Ph}^{1}$ chromosome was detected in long term culture. ${ }^{5}$ The bcr/abl rearrangement has been consistently absent in the few cases in which relevant studies have been done but the need for more data has also been stressed. ${ }^{3}$ The presence of the bcr/abl rearrangement in the case reported here suggests that the repertoire of the phenotypic expression of the hybrid bcr/ abl gene might include a disorder closely resembling CNL. This calls for redefinition of the diagnostic criteria for CNL to include the absence of $\mathrm{bcr} / \mathrm{abl}$, as a projection of the generally accepted requirement for absence of a $\mathrm{Ph}^{1}$ chromosome. Even so, cases like the one presented here will remain difficult to classify, reflecting the presence of a continuum within the myeloproliferative group of chronic myeloid leukaemias.

1 Lichtman MA. Chronic myelogenous leukemia and related disorders. In: Williams WJ, Beutler E, Lichtman MA, Coller BS, Kipps TJ, eds. Hematology. New York: McGrawHill, 1995:309-10.

2 Virgolini L. Leucaemia neutrofila. Revisione della letteratura. Min Med 1985;76:1951-6.

3 Zittoun R, Rea D, Ngoc LH, Ramond S. Chronic neutrophilic leukemia. A study of four cases. Ann Hematol 1994;68:55-60.

4 Southern EM. Detection of specific sequences among DNA fragments separated by gel electrophoresis. $7 \mathrm{Mol} \mathrm{Biol}$ ragments separate

5 Sanada I, Yamamoto S, Ogata M, Kawakita M, Kawano F, Fujiwara $\mathrm{H}$, et al. Detection of Philadelphia chromosome in chronic neutrophilic leukemia. Ipn f Clin Oncol 1985;15: 553-8.

6 Zago MA, Figueiredo MS, Covas DT, Bottura C. Aspects of splenic hypofunction in old age. Klin Wochenschr 1985;63: $590-2$.

\title{
Myxoid renal cell carcinoma: histological, immunocytochemical and ultrastructural study
}

\author{
H A Birch, J M Glass, J Vale, $M$ M Walker
}

Department of

Histopathology, St

Mary's Hospital, Praed

Street, Paddington,

London W2 1NY

H A Birch

M M Walker

\section{Department of}

Urology

J M Glass

J Vale

Correspondence to: Mr Jonathan Glass.

\begin{abstract}
Renal cell carcinomas show a variety of histological features. A case of a renal tumour arising in a 44 year old African man is reported. The tumour was composed of a cobweb-like pattern of narrow anastomising tubules lined by cuboidal cells separated by a hypocellular myxoid stroma. Immunohistochemical stains were consistent with a renal cell origin. The differential diagnosis in these cases includes sarcoma.
\end{abstract}

(F Clin Pathol 1996;49:1015-1017)

Keywords: renal cell carcinoma, histological variants.

Renal cell carcinomas exhibit a wide variety of cytological and architectural appearances. Chromophilic tumours (of eosinophilic or basophilic type) usually exhibit a tubulopapillary growth pattern with cells separated by a small volume of fibrovascular stroma. ${ }^{1}$ Here, we report an unusual chromophilic renal cell carcinoma with a microtubular growth pattern and abundant myxoid stroma.

\section{Case report}

A 44 year old African man presented with intermittent loin pain and haematuria. He had been hypertensive for 10 years and had a history of childhood schistosomiasis. He was a non-smoker with no risk factors for renal o disease. There was a family history of hypertension. A renal ultrasound scan revealed a mass in the left kidney, which was confirmed on computed tomography scanning. A radical nephrectomy was performed and the patient was discharged home seven days later. $\mathrm{He}$ remains well 12 months after the operation.

\section{Pathological findings}

Macroscopically, the kidney contained a well defined rounded tumour, $3.6 \mathrm{~cm}$ in diameter, within the cortex of the upper pole, confined within the renal capsule and with a soft yellow cut surface with areas of haemorrhage. The remaining renal tissue was macroscopically normal. Five representative samples of the tumour were taken for histological examination. Microscopically, all sections showed that the tumour was composed of a cobweb-like 


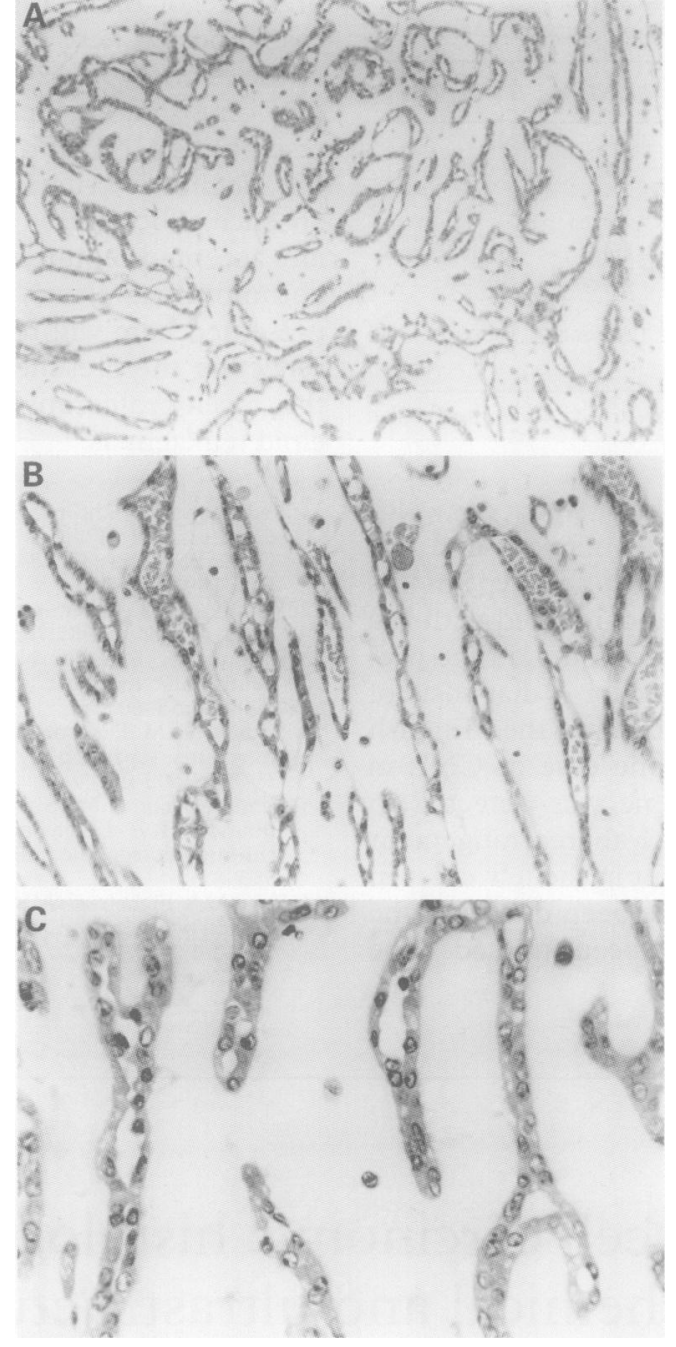

Figure 1 Typical sections through the tumour showing tubules of cuboidal cells with finely granular eosinophilic cytoplasm, separated by a hypocellular myxoid stroma. (A) Original magnification $\times 40$; $(B)$ and $(C)$ original magnification $\times 100$.

pattern of narrow anastomising tubules lined by cuboidal cells. These cuboidal cells had indistinct cell boundaries and contained irregular ovoid nuclei, small nucleoli and finely granular eosinophilic cytoplasm, separated by a hypocellular myxoid stroma containing a mild infiltrate of macrophages and lymphocytes (fig 1). In places, the tubules formed whorls surrounding small blood vessels. The appearances were similar throughout the tumour. There were no areas of acinar, papillary or cystic architecture or clear cell differentiation more typical of renal cell carcinoma. Areas of haemorrhage were present but there was no necrosis. No mitotic activity was present. No lymphatic or vascular invasion was seen and a hilar lymph node was negative for tumour cells. The stroma stained positively for acid mucopolysaccharide (positively with alcian blue and periodic acid-Schiff with diastase pretreatment). The cell cytoplasm was negative on staining for mucin, glycogen and fat.

Immunocytochemical staining was positive for cytokeratin (AE1/3 and CAM 5.2), vimentin and epithelial membrane antigen; and negative for desmin, smooth muscle actin, S100 protein, chromogranin and QBend10. Transmission electron microscopy showed that the cytoplasm was relatively empty, but rough
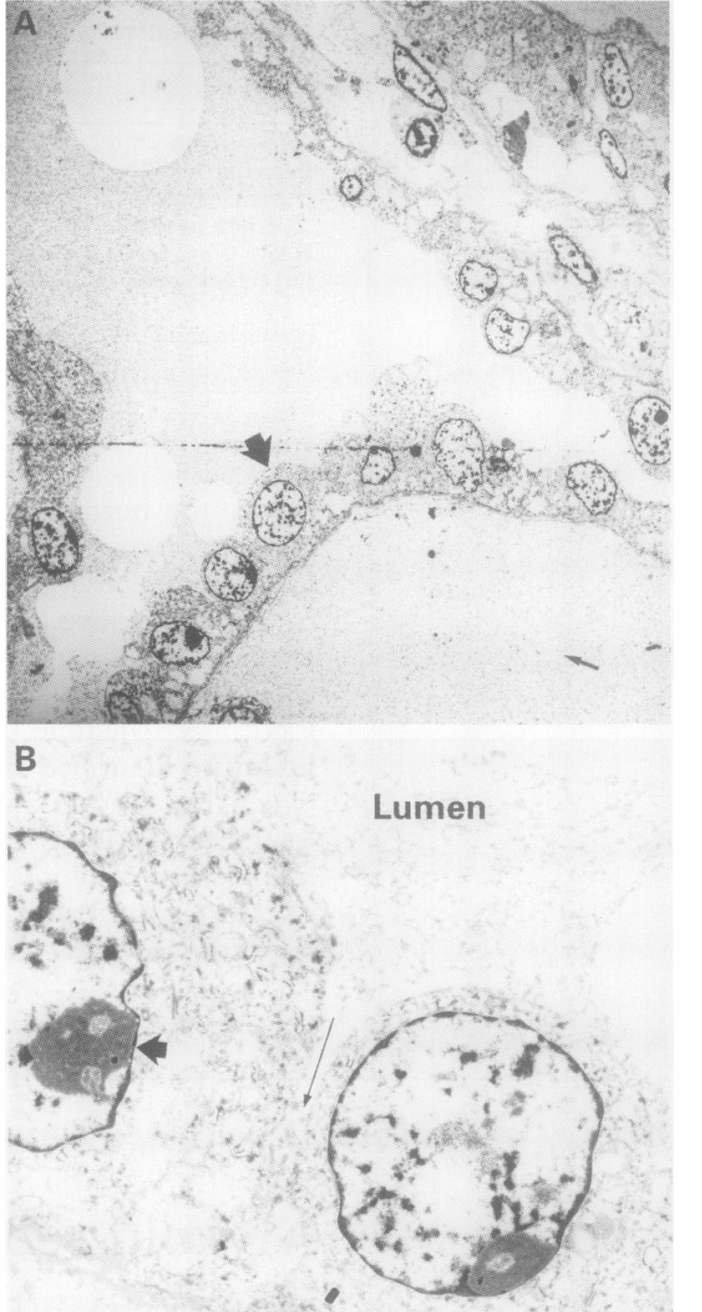

\section{Stroma}

Figure 2 Representative transmission electron micrograph showing $(A)$ a single layer of cuboidal cells with relatively empty cytoplasm (wide arrow) with myxoid stroma (narrow arrow) (original magnification $\times 995$ ) and $(B)$ the same cells with irregular nuclei, prominent nucleoli (wide arrow) and indistinct cell boundaries (narrow arrow). The lumen and stroma contain similar matter (original magnification $\times 6000$ ).

endoplasmic reticulum, free ribosomes, small aggregates of glycogen and the occasional microvesical and dense bodies were present (fig 2). No lipid was present. The nuclei contained clumped and peripherally condensed chromatin and fibrillar matter. The cells rested on a duplicated basement membrane and were joined by desmosomes. No tight junctions were identified and the granular stroma matter, which contained a little glycogen, was also present in the tubular lumen.

\section{Discussion}

Renal cell carcinomas exhibit a range of cytological and architectural appearances. They are most commonly composed of cells with optically clear cytoplasm rich in glycogen and lipid (the classic clear cell carcinoma). They can, however, contain chromophilic cells 
which appear eosinophilic if the cytoplasm is plentiful and rich in mitochondria, or basophilic if more scanty with fewer mitochondria. Clear cell and chromophilic cell types of renal cell carcinomas co-express cytokeratin and vimentin and are thought to be derived from the proximal convoluted tubule. ${ }^{23}$ These cell types are commonly seen together in any one tumour. De-differentiated 'sarcomatoid' spindle cell forms of renal cell carcinomas are also seen. Some tumours are composed of pale chromophilic cells containing microvesicles but little glycogen or lipid, which express cytokeratin but not vimentin and are thought to be derived from the intercalated cells of the collecting duct.

Solid, acinar, trabecular, or tubulo-papillary architectural patterns may also be seen, frequently in combination, in any one tumour. ${ }^{1}$ Secondary changes such as cystic degeneration, haemorrhage and necrosis are also common in renal cell carcinomas.

There is some association between cell type and architectural pattern with the clear cell and chromophobic tumours producing a more solid compact pattern, whereas the chromophilic cell types usually produce a tubulopapillary pattern, with papillae containing fibrovascular cores. ${ }^{1}$ The pure papillary variant contains prominent numbers of macrophages with foamy cytoplasm in the papillary cores.

In the present case the tumour described is a chromophilic renal cell carcinoma (Fuhrman grade $2, \mathrm{~T} 2 \mathrm{~N} 0 \mathrm{Mx}$, stage 2$)^{4}$ which is poor in mitochondria for the degree of eosinophilia present and has an unusual microtubular growth pattern and myxoid stroma. The tumour was monomorphic throughout. The absence of other degenerative changes suggests that the myxoid stroma is a primary component of the tumour.

The prognosis of renal cell carcinomas depends on the nuclear grade and the stage, and is independent of the tumour cell type and architecture, except for the sarcomatoid and papillary tumours which fare worse. ${ }^{5}$ The clinical significance of the unusual tumour pattern described here is doubtful, but it has not been reported previously. The unusual appearance is a potential source of diagnostic errorother myxoid tumours, such as myxoid chondrosarcoma or leiomyosarcoma, may appear similar on initial microscopic inspection-but immunohistochemistry will provide the diagnosis.

1 Thoenes W, Storkel S, Rumpelt HJ. Histopathology and classification of renal cell tumors (adenomas, oncocytomas, and carcinomas). The basic cytological and histopathological es for diagnostics. Pathol Res Pract cal elements and their

2 Pitz S, Moll R, Storkel S, Thoenes W. Expression of intermediate filament proteins in subtypes of renal cell carcinomas and in renal oncocytomas. Lab Invest 1987;56:642-53.

3 Gerharz C-D, Moll R, Storkel S, Ramp U, Thoenes W, Gabbert HE. Ultrastructural appearances and cytoskeletal architecture of the clear, chromophilic and chromophobe types of human renal cell carcinoma in vitro. Am $¥$ Pathol types of human renal cell carcinoma in vitro. Am f Pathol $\mathbb{Q}$

4 Furhman SA, Lasky LC, Limas C. Pathological significance of morphological parameters in renal cell carcinoma. $A m \mathcal{F}$ Surg Pathol 1982;6:655-63.

5 Nasady T, Bane BL, Silva FG. Chapter 41. Adult renal diseases. Sternberg SS, Antonioli DA, Carter D, Mills SE, Oberman HA, eds. Diagnostic surgical pathology. 2nd edn. New York: Raven Press, 1994:1645-739.

\section{Helicobacter pylori antibody titres in serum, plasma and successively thawed specimens: implications for epidemiological and clinical studies}

Department of Public

Health and

Community Medicine,

Ballarat Base Hospital,

University of

Melbourne

D C Pearce

H G Peach

Epidemiology and Biostatistics Unit S J Farish

Correspondence to: Ms D C Pearce, Department of Public Health and Community Medicine, Ballarat Base Hospital, PO Box 577, Ballarat VIC 3353 Australia.

Accepted for publication 4 September 1996

\author{
D C Pearce, H G Peach, S J Farish
}

\begin{abstract}
Agreement between Helicobacter pylori IgG antibodies measured using the Pyloriset EIA-G kit in serum, plasma and successively thawed specimens was studied and the implications for epidemiological and clinical studies assessed. Plasma titres may differ from serum titres by $-6 \%$ to $+8 \%$ and therefore may be substituted for serum. The change in titre around the cut off value was -0.31 (se $=5.7, p=0.96$ ) per thaw. The estimated maximum drop after three thawings, 34.5 , would result in only a small decrease in sensitivity (1.3\%).
\end{abstract}

For qualitative epidemiological studies, $\stackrel{\mathscr{\infty}}{+}$ this additional misclassification rate is 0 relatively small. However, positive titres did reduce over successive thawings, with

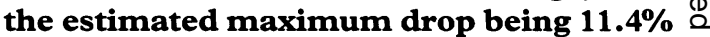
per thaw. Therefore, thawing does need to be considered as a contributing factor 8 when interpreting titre drops in eradication trials. Baseline and follow up speci- 흘 mens from clinical studies should be $\supsetneq$ thawed once only and tested concurrently. (F Clin Pathol 1996;49:1017-1019)

Keywords: Helicobacter pylori, epidemiology, serology. 